\title{
Development Status of the C2C E-commerce Express in China: Case Study on Taobao
}

\author{
Lianhong DING ${ }^{a}$, Xiaotong DENG ${ }^{b}$ and $Y u X{ }^{\prime} O^{c}$ \\ School of Information, Beijing Wuzi University, Beijing 101149, China



\begin{abstract}
Keywords: C2C E-commerce, express, regional difference, outbound express, express surplus Abstract. Taobao is the biggest platform for $\mathrm{C} 2 \mathrm{C}$ e-commerce in China. Based on the data of expresses from taobao.com, this paper conducts a statistical analysis about the $\mathrm{C} 2 \mathrm{C}$ express in China under 31 provinces, three economic zones and eight economic regions, respectively. $\mathrm{C} 2 \mathrm{C}$ expresses related with each area are classified into outbound expresses and inbound expresses according to their recipient addresses and sender addresses. The development of $\mathrm{C} 2 \mathrm{C}$ expresses in China is unbalanced and the difference of outbound expresses between areas is much higher than the inbound expresses. Concepts of express surplus and express deficit are put forward based on the definition of trade surplus and trade deficit. Statistical results show only 4 provinces' C2C expresses are surplus, the rest are all deficit. We found that $84.2 \%$ of $\mathrm{C} 2 \mathrm{C}$ expresses in China are distributed across different provinces. Delivery distances of $\mathrm{C} 2 \mathrm{C}$ expresses across different provinces are calculated as well. Delivery distance for most $\mathrm{C} 2 \mathrm{C}$ trans-provincial expresses is bigger than $500 \mathrm{~km}$ and less than 1500 $\mathrm{km}$.
\end{abstract}

\section{Introduction}

According to the report of China National Bureau of Statistics, the total retail sales of consumer goods in China had exceeded 33 trillion RMB in 2016. The development of the Internet and popularization of information technology promoted the development of e-commerce. Chinese online shopping accounted for $12 \%$ of total retail sales of consumer goods in 2016 and the proportion continues to grow. Rapid development of e-commerce accelerates the development of express industry further. The latest data from China Post Bureau shows that Chinese express delivery business reached 31.35 billion in 2016 with an increase of $51.7 \%$, and ranked first in the world.

Electronic commerce is the electronically facilitated transactions. E-commerce can be classified into business-to-business (B2B), business-to-consumer (B2C), and consumer-to-consumer (C2C) commerce, according to the types of participating parties. $\mathrm{C} 2 \mathrm{C}$ e-commerce is business between individuals and individuals. Due to the individual sellers, trust and reputation have become a research hotspot in C2C [1-4]. Some researchers focus on the study of purchasing pattern, payment pattern, website evaluation and service quality [5-8].

Taobao (www.taobao.com), provided by Alibaba, is the Chinese largest platform for C2C. It owns 500 million registered users and 120 million daily active users. Taobao has $95.1 \%$ market share of $\mathrm{C} 2 \mathrm{C}$ in China and plays an absolute dominant position. The features of Taobao represent the development status of $\mathrm{C} 2 \mathrm{C}$ e-commerce in China. Spatial and temporal distribution of $\mathrm{C} 2 \mathrm{C}$ e-commerce and express delivery industry has received attention from academics. Wang et al. found that there were very significant and positive spatial autocorrelations in the development of C2C e-commerce in different regions of China [9]. Zheng et al. used the spatial autocorrelation model and suitability model to analyze and compare the spatial distribution characteristics of C2C e-shops and logistics nodes [10]. Theil index is applied by Jin et al. to study the difference in the development trend of Chinese regional logistics [11]. There are few study about the space-time difference in the development of express industry. An important reason is that it is difficult to obtain related data. On the one hand, the statistical data of Chinese National Statistical Yearbook and Local Statistical Yearbook are incomplete. On the other hand, most enterprises don't want to open their business data. Based on the business data from a third party logistics company, this paper analyzes the status of $\mathrm{C} 2 \mathrm{C}$ express in China. 


\section{Data Preprocessing and Area Division}

The basement of this paper is the data set supplied by a third party logistics company. This data set includes the company's 4 months delivery businesses for Taobao. There are more than 970,000 C2C expresses of China, covering 31 provinces, municipalities and autonomous regions. The complete information of each express is described as a record in the data set. Due to the trade secrets, information such as sender and recipient are deleted. Because we focus on the geographical distribution and flow direction of express business, for each delivery, only the information about province and city in the detail address is reserved.

In order to find the development status of $\mathrm{C} 2 \mathrm{C}$ e-commerce express delivery in different areas in China, three methods for regional division are adopted in this paper. The smallest units are the 31 provinces, municipalities and autonomous regions in the administrative areas of China. The medium units are eight economic regions of China. They are northeast, northern coast, eastern coast, southern coast, middle reaches of the Yellow River, middle reaches of Yangtze River, southwest and northwest respectively. The largest units are three economic zones. They are east zone, middle zone and west zone.

Table 1 Three economic zones

\begin{tabular}{|l|l|}
\hline Economic zone & Districts included \\
\hline East zone & $\begin{array}{l}\text { Beijing, Tianjin, Liaoning, Shanghai, Jiangsu, Zhejiang, Fujian, Shandong, } \\
\text { Guangdong and Hainan }\end{array}$ \\
\hline Middle zone & Shanxi, Jilin, Heilongjiang, Anhui, Jiangxi, Henan, Hubei and Hunan \\
\hline West zone & $\begin{array}{l}\text { Guangxi, Inner Mongolia, Chongqing, Sichuan, Guizhou, Yunnan, Xizang, } \\
\text { Shaanxi, Gansu, Qinghai, Ningxia and Xinjiang }\end{array}$ \\
\hline
\end{tabular}

According to both the level of economic technology and geographical location, China's seventh "Five-year Plan" divided Chinese economic area into three economic zones. China's eleventh "Five-year Plan"divided Chinese economic area into eight economic regions. The provinces, municipalities and autonomous regions that constitute the economic regions and three economic zons are listed in Table 1 and Table 2 respectively.

Table 2 Eight economic regions

\begin{tabular}{|l|l|}
\hline Economic regions & Districts included \\
\hline Northeast & Liaoning, Jilin and Heilongjiang \\
\hline Northern coast & Beijing, Tianjin, Hebei and Shandong \\
\hline Eastern coast & Shanghai, Jiangsu and Zhejiang \\
\hline Southern coast & Fujian, Guangdong and Hainan \\
\hline Middle reaches of the Yellow River & Shanxi, Inner Mongolia, Shaanxi and Henan \\
\hline Middle reaches of Yangtze River & Hubei, Hunan, Anhui and Jiangxi \\
\hline Southwest & Guangxi, Sichuan, Guizhou and Yunnan \\
\hline Northwest & Xinjiang, Gansu, Qinghai and Ningxia \\
\hline
\end{tabular}

\section{Outbound Express and Inbound Express}

In order to master the direction of $\mathrm{C} 2 \mathrm{C}$ expresses, all expresses related with each area are classified into outbound expresses and inbound expresses according to recipient address and sender address. The outbound expresses for an area are the packages whose sender address is in the area and the inbound expresses for an area are the packages whose recipient address is in the area.

The outbound expresses and inbound expresses for 31 provinces, municipalities and autonomous regions are calculated respectively. The top five provinces of $\mathrm{C} 2 \mathrm{C}$ outbound express are Guangzhou, Zhejiang, Fujian, Shanghai, and Beijing. These five provinces account for $82.4 \%$ of the total. The lowest five provinces of $\mathrm{C} 2 \mathrm{C}$ outbound express are Xizang, Gansu, Xinjiang, Ningxia, and Qinghai. They only account for $0.03 \%$ of the total. The top five provinces of $\mathrm{C} 2 \mathrm{C}$ inbound express are Guangzhou, Jiangsu, Zhejiang, Beijing, and Shanghai. These five provinces account for $51.3 \%$ of the total. The lowest five provinces of $\mathrm{C} 2 \mathrm{C}$ inbound express are Xinjiang, Gansu, Ningxia, Xizang, and Qinghai. These five provinces only account for $1.67 \%$ of total. It can be found that the concentration 
of regional distribution of $\mathrm{C} 2 \mathrm{C}$ outbound express is more notable than inbound express in provincial regions. Simultaneously, only the $\mathrm{C} 2 \mathrm{C}$ express business in eight provinces exceeded the average, which further reflected the striking gap in the development level of $\mathrm{C} 2 \mathrm{C}$ express in various provincial regions in China.

The outbound expresses and inbound expresses for eight economic regions and three economic zones are counted as well. The southern coast, eastern coast, and northern coast are top three both in the outbound expresses and the inbound expresses. Their proportions in the total of outbound expresses are $46.4 \%, 35.4 \%$, and $9.5 \%$ respectively. Their proportions in the inbound expresses are $27.0 \%, 21.5 \%$, and $18.0 \%$ respectively. Only southern coast and eastern coast exceeded the average. They account for more than $81.8 \%$ of the total amount of outbound expresses and $66.5 \%$ of the total amount of inbound expresses. These numbers show coast areas are dominated in the eight economic regions.

For three economic zones, east zone accounts for $92.2 \%$ of the total amount of outbound express and $69.6 \%$ of the total amount of inbound express. Middle zone accounts for $4.5 \%$ and $15.1 \%$, west zone accounts for $3.3 \%$ and $15.3 \%$.

\section{Express Surplus and Express Deficit}

According to the definitione of trade surplus and trade deficit, we introduce the express surplus and express deficit into the analysing of $\mathrm{C} 2 \mathrm{C}$ express in China. For an area, if the number of its outbound expresses is bigger than its inbound expresses, it is called an express surplus, positive balance, or a "favorable balance". Conversely, if an area's inbound expresses is greater than its outbound expresses, it is called an express deficit, negative balance, or "unfavorable balance".

For 31 provinces, municipalities and autonomous regions, only four of them are express surplus. They are Zhejiang, Guangdong, Fujian, and Shanghai. The rest 27 provinces, municipalities and autonomous regions are express deficit. For eight economic regions, eastern coast and southern coast are express surplus. For three economic zones, only east zone is express surplus.

\section{Delivery Distance}

We call the express whose recipient address and sender address belong to one province, as provincial express. The express whose departure province and destination province are different is named as trans-provincial express. Provincial express only accounted for $15.8 \%$ of the entire $\mathrm{C} 2 \mathrm{C}$ expresses. This paper focuses on the analysis of the delivery distance of the trans-provincial expresses.

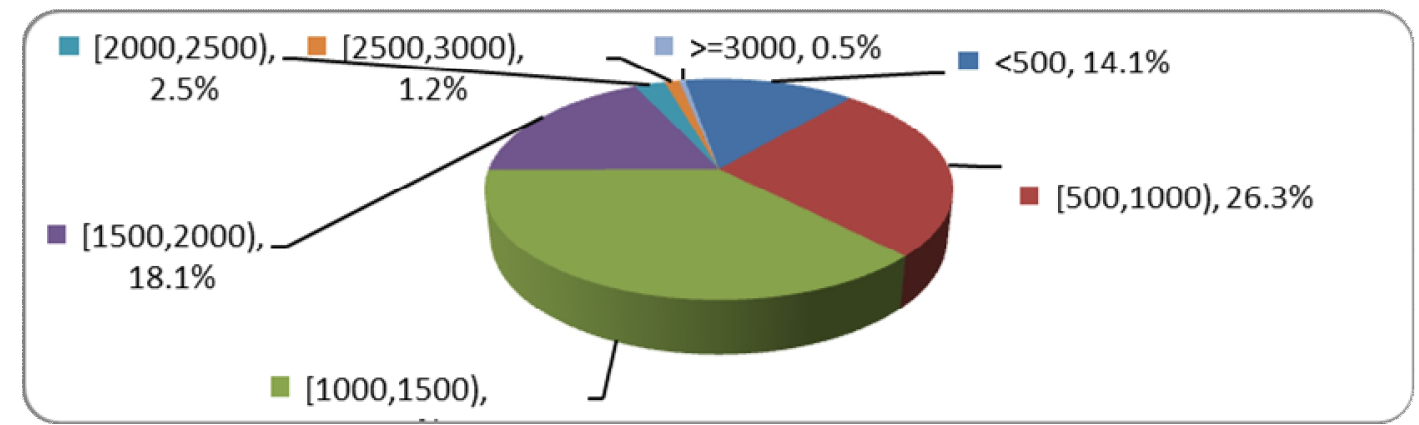

Figure 1 Proportion for delivery distances of trans-provincial expresses

The shortest distance is the delivery between Beijing and Tianjin and the longest distance is the delivery between Xizang and Heilongjiang. Fig. 1 illustrates the proportions of distances that less than $500 \mathrm{~km}$, between $500 \mathrm{~km}$ and $1000 \mathrm{~km}$, between $1000 \mathrm{~km}$ and $1500 \mathrm{~km}$, between $1500 \mathrm{~km}$ and $2000 \mathrm{~km}$, between $2000 \mathrm{~km}$ and $2500 \mathrm{~km}$, between $2500 \mathrm{~km}$ and $3000 \mathrm{~km}$ respectively. The result shows that most $\mathrm{C} 2 \mathrm{C}$ expresses are trans-provincial expresses. The distance for most trans-provincial expresses is between $500 \mathrm{~km}$ and $1500 \mathrm{~km}$. 


\section{Conclusions}

The development level of $\mathrm{C} 2 \mathrm{C}$ express between Chinese 31 provincial regions is very different. The differences among regions decrease with the increasing of dipartite granularity. The classification of express delivery can better analyze the profitability and consumption capability of $\mathrm{C} 2 \mathrm{C}$ e-commerce in each region in China. Hence, statistic and analyze the departure, arrival and the total respectively is necessary. The difference of the $\mathrm{C} 2 \mathrm{C}$ outbound express is significantly higher than the inbound express, indicating that the difference of profitability level of C2C e-commerce in Chinese is huge while the difference of purchasing ability of $\mathrm{C} 2 \mathrm{C}$ e-commerce in Chinese is slight. Chinese $\mathrm{C} 2 \mathrm{C}$ e-commerce expresses are mainly trans-provincial expresses. The delivery distance for most trans-provincial expresses is between $500 \mathrm{~km}$ and $1500 \mathrm{~km}$.

\section{Acknowledgements}

This work was supported by Beijing Key Laboratory (NO. BZ0211), Beijing Intelligent Logistics System Collaborative Innovation Center and Reform Project in BWU Postgraduate Education.

\section{References}

[1] Jones K, Leonard L N K. Trust in consumer-to-consumer electronic commerce [J]. Information \& Management, 2008, 45(2):88-95.

[2] Yucui W, Xiaofen X. The Research on C2C e-Commerce Credit System.[C]// International Conference on E-Business and E-Government. IEEE, 2010:4936-4937.

[3] Wu F, Li H H, Kuo Y H. Reputation evaluation for choosing a trustworthy counterparty in C2C e-commerce[J]. Electronic Commerce Research \& Applications, 2011, 10(4):428-436.

[4] Wei B, Feng D, Liu J. C2C E-commerce Risk Assessment Based on AHP and Fuzzy Comprehensive Evaluation[J]. International Journal of Engineering \& Manufacturing, 2011, $1(1)$.

[5] Tian Y, Ye Z, Yan Y, et al. A practical model to predict the repeat purchasing pattern of consumers in the $\mathrm{C} 2 \mathrm{C}$ e-commerce[J]. Electronic Commerce Research, 2015, 15(4):571-583.

[6] Xiong J, Yao L. Anomalous Collusion Detection in Third Party Payments Using K-Means Cluster[M]// Advances in Electrical Engineering and Electrical Machines. Springer Berlin Heidelberg, 2011:549-556.

[7] Qie H, Liu J. The Research on the Electronic Commerce Service Quality Indicators in C2C Field[M]// LISS 2014. Springer Berlin Heidelberg, 2015:523-534.

[8] Huang L, Li M. Research on C2C e-commerce website usability evaluation system[C]// IEEE, International Conference on Computer-Aided Industrial Design \& Conceptual Design. IEEE, 2010:1371-1374.

[9] Wang X, Shenmeng X U. Geographical Distribution of C2C Taobao Online Stores in China[J]. Progress in Geography, 2011, 30(12):1564-1569.

[10]ZHENG Wen-sheng, JIN Li-juan, et al. Relation of District Distribution between C2C E-Shops and Logistics Network in China, Economic Geography, 2016,(03):83-90.

[11]Jin F H, Xu X U, University S D. Research on the Unbalanced Development Trend of China's Regional Logistics Based on Theil Index[J]. China Business \& Market, 2014. 